\title{
Assessment of dentofacial variations in monozygotic twins Victor $\mathrm{Tu}^{1}$
}

${ }^{1}$ University of Pittsburgh, School of Dental Medicine

\section{Abstract}

With dentofacial development being a multifactorial process, we face the question of whether genetic or environmental factors play a larger role in specific phenotypic traits. The use of twin studies allows one to employ genetic controls to the study such that one can focus solely on traits that may be more environmentally determined. This study involves retrospective as well as current analytical measurements between a set of monozygotic twins to assess genetic and outside influences on facial and intraoral development. While similarities were acknowledged, we found differences in measurements of the facial thirds, the congenital presence of mandibular third molars, and the presence of mandibular tori.
Citation: Tu, V. (2017) Assessment of dentofacial variations in monozygotic twins. Dentistry 3000. 1:a001 doi:10.5195/d3000.2017.76

Received: May 22, 2017

Accepted: May 26, 2017

Published: June 16, 2017

Copyright: (C2017 Tu, V. This is an open access article licensed under a Creative Commons Attribution Work 4.0 United States License.

Email:vwt2@pitt.edu

\section{Introduction}

Dentofacial development is a multifactorial phenomenon that relies on the interactions between multiple genes, environmental contributions and epigenetic factors that all come together like pieces of a puzzle to yield a definitive set of phenotypic attributes. Much of the studies on dentofacial characteristics and pathologies have been focused on the contributing role of genetics in the hopes of being able to utilize it as a tool in diagnosis and treatment planning. This has led to the confirmation that genetic inheritance is the controlling factor in facial formation through craniometrical and cephalometric studies of facial similarities. Furthermore, similarities in craniofacial bones and profiles are observed when cephalograms of siblings are superimposed on that of their parents $[5,6]$. However, the use of monozygotic twin studies has also helped to elucidate how heredi- tary and environmental factors mesh with one another to create the final physical result. This is attributed to the reasoning that any differences observed in a physical feature between monozygotic twins that are genetically identical implies that environmental factors may play a significant role in that aspect of a person compared to the other more genetically controlled phenotypes. Past studies between monozygotic adult twins have uncovered differences in measurements of the anterior cranial base, mandibular body length, total facial height, and lower facial height [1].

\section{Further-}

more, another study on dental arch forms and size demonstrated that the effect from environmental factors were more at play for this part of development rather than genetics alone [2]. Another study on dental arch forms and the structure of individual teeth of several monozygotic twin pairs showed that twins are not necessarily always occlusally identical [4]. An analysis on 42 pairs of twins found hereditary factors to be responsible for only $40 \%$ of the total skeletal and dental features that caused malocclusion with the genetic component being more of a determining factor for skeletal features than dental features [3]. 


\begin{tabular}{|l|l|l|}
\hline \multicolumn{3}{|l|}{ Table 1. Facial Measurements between Twin A and Twin B. } \\
\hline & Twin A & Twin B \\
\hline Width of Mouth & $50 \mathrm{~mm}$ & $50 \mathrm{~mm}$ \\
\hline Distance Between Eyes & $42 \mathrm{~mm}$ & $40 \mathrm{~mm}$ \\
\hline Alar of Nose & $35 \mathrm{~mm}$ & $37 \mathrm{~mm}$ \\
\hline Width of Eye & $34 \mathrm{~mm}$ & $36 \mathrm{~mm}$ \\
\hline Facial Thirds (upper) & $65 \mathrm{~mm}$ & $66 \mathrm{~mm}$ \\
\hline Facial Thirds (middle) & $60 \mathrm{~mm}$ & $70 \mathrm{~mm}$ \\
\hline Facial Thirds (lower) & $70 \mathrm{~mm}$ & $65 \mathrm{~mm}$ \\
\hline Interlabial Gap at Rest & $5 \mathrm{~mm}$ & $5 \mathrm{~mm}$ \\
\hline Upper Lip Length & $24 \mathrm{~mm}$ & $24 \mathrm{~mm}$ \\
\hline Upper Lip to Incisal Edge & $2 \mathrm{~mm}$ & $2 \mathrm{~mm}$ \\
\hline
\end{tabular}

However, genes that regulate facial proportions and jaw relationships may still play an indirect role in determining occlusion.

Regardless, occlusal relations seem to be more effected by the environment. As with any multifactorial process, there is debate in terms of whether genetic or environmental factors are weighted more in terms of the final outcome. Twin studies offer the chance to gain insight into whether there are other factors at play in terms of development when genetic factors are controlled for.

\section{Subjects and Methods}

This study involves retrospective sources and current facial measurements to gauge differences in dentofacial development between twin A and twin B. In addition to past photographs (Figure 1), current facial measurements were taken to help assess differences in a quantitative way (Table 1). While most of the measurements were self-explanatory, the first facial third was taken as the distance between the trichion and the glabella. The middle third is the distance from the glabella to the subnasale. Finally, the lower third was measured from the subnasale to the menton. Twins $A$ and $B$ are currently under Invisalign treatment. Patient treatment diagrams from the start of treatment are shown in figure 2 to provide a snapshot of the occlusion before treatment. Past bitewing radiographs combined with current intraoral pictures were taken to assess the oral condition (Figure 3 ).

\section{Results and Discussion}

Dentofacial development is a multifactorial process but it is unknown how involved environmental factors are in particular

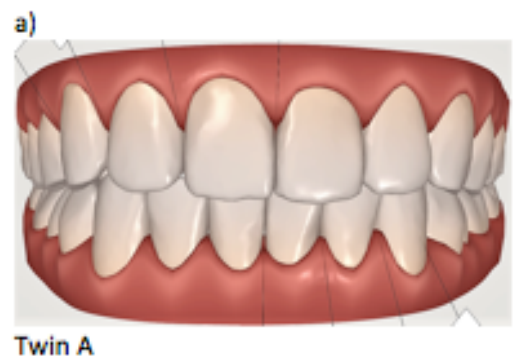

as these twins mature in growth and development, these differences are magnified. To assess these measurements in a quantitative fashion, facial measurements were taken between twin A and twin $B$, which presents largely a general consensus in facial outcome. Of greatest interest is the difference in measurement in the middle and lower thirds of the face, where one finds the greatest amount of dissimilarity. One plausible explanation is based on the growth pattern of the lower half of the face. Lower facial development occurs at relatively fewer growth sites and over a more extended period of time compared to the upper half of the face [1]. The form and size of the upper facial region is dependent on numerous elements that interact in a more complex set of pathways [1]. With less growth sites on the lower half of the face, one can extrapolate that genetic factors are less involved in lower facial devel-

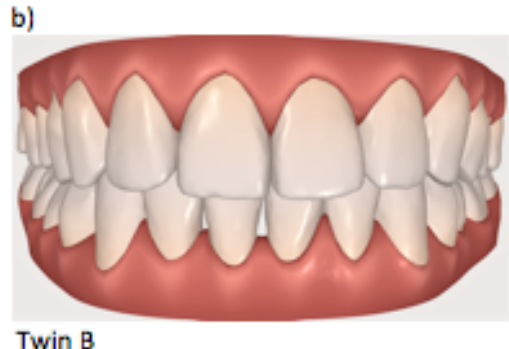

|Figure 2. Dental occlusion at the start of Invisalign therapy for Twin A and Twin B.

aspects of the final outcome. Assessing the photos in Figure 1, one should be able to detect subtle differences already between twin $A$ and twin $B$ after birth. Over time opment, which opens the door for environmental factors to leave a greater impact in facial development of the lower half. 


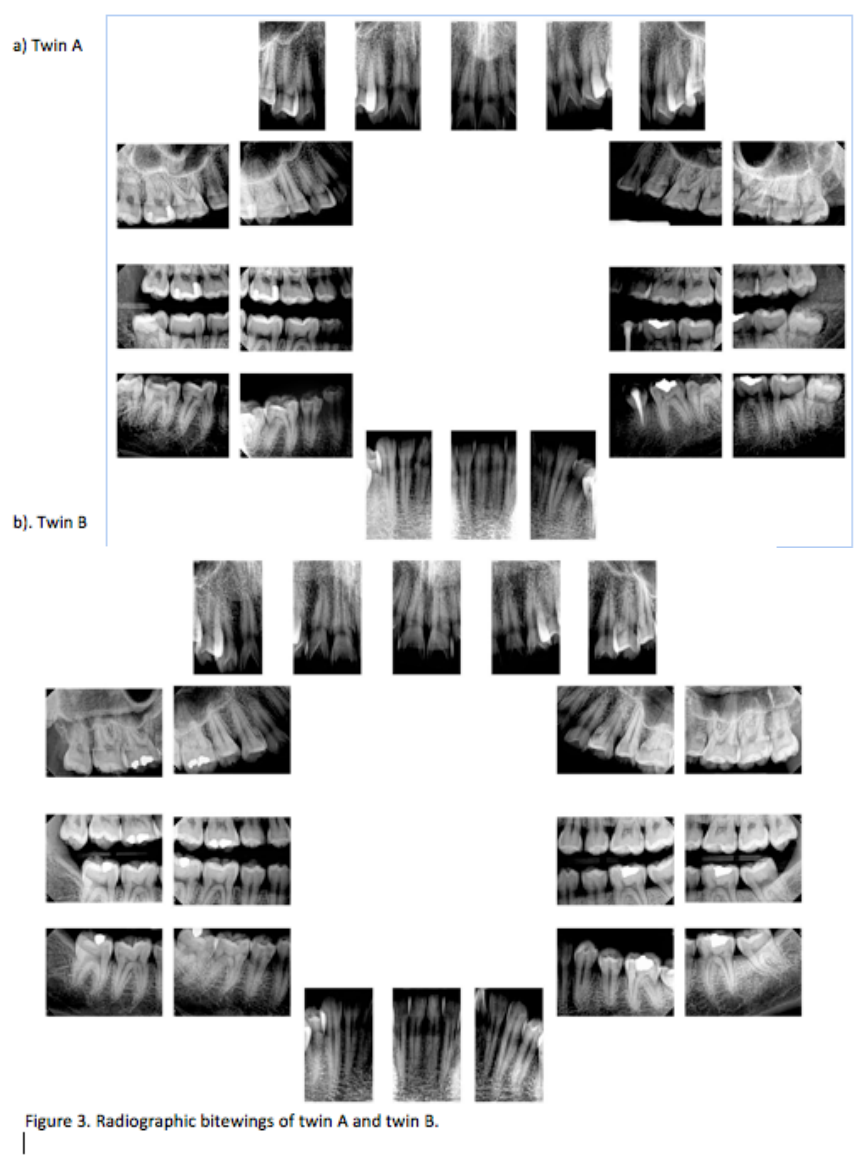

mental factors such as differences in tooth brushing technique is a plausible explanation for this.

Assessing the bitewing radiographs between the two siblings, the presence of existing restorations was used to determine caries susceptibility. Based on the radiographs, both siblings have three restorations with twin A having restorations on numbers 2 (MO), 19 (O), and 20 (endo-

Despite the fact that previous studies have found that environment contributes significantly to the development of arch form and size and dental occlusion, there are still a lot of occlusal similarities between twin A and B. Despite the assumption that genetics is less involved in the lower half of the face, both twins present with shifted midlines yet maintain a class I occlusal relationship. The only striking dissimilarities that can be observed is that there is spacing between the mandibular anterior teeth of twin B whereas that space is closed in twin A with the cervical necks of the mandibular incisors tipped more mesially. The gingival margins also appear to be more rounded in twin $A$ and more pointed in twin B. Environdontic treatment). Twin $B$ has restorations on numbers 3 (O), 19 (O), and 31 (O). As the presentation of carious lesions follows a multifactorial causation that relies on the balance between the host (protective mechanisms like salivary flow rate) and environmental factors (diet and indigenous bacterial flora), it would not be a surprise if the twins differed in caries presentation as genetic similarities alone cannot determine caries risk. The similarities seen in this case can be attributed to household with similar habits in digrowing in the same eting and oral hygiene. This may not be the case if the siblings were separated at birth. It is also intriguing to note that the twins present with differences in mandibular third molar formation. While twin A retained his third molars to the age of 23 , twin $B$ is congenitally missing number 32 . Also as a child, twin B's number 18 was severely broken down by caries that it was extracted and number 17 was allowed to erupt into its place. Moreover, the root tips on number 17 are divergent compared to twin B's, which is noticeably convergent apically. This supports the idea that third molars are very susceptible to developmental variation despite identical genetics, which places importance on environmental influences. Intraoral pictures in figure 4 further reveal that twin A possesses a mandibular torus behind number 21. Twin B, on the other hand, possesses bilateral mandibular tori behind both premolars (\#21 and \#27). Mandibular tori are commonly present early in adult life and are associated with several factors including bruxism, local stresses, and genetic influences. In

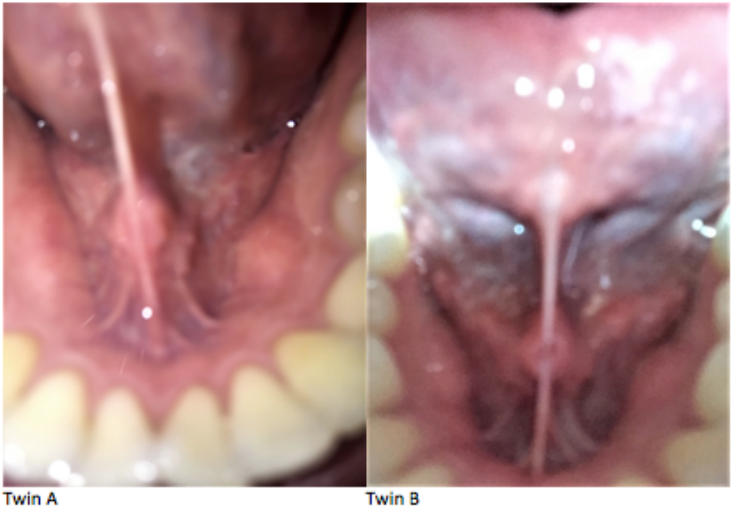

|Figure 4. Intraoral photograph of twin A (right) compared to that of twin B (left). A mandibular torus is present unilaterally on the lingual ridge behind \#21 for twin A. Twin B exhibits a bilateral presentation of a mandibular tori situated behind both first premolars. 
this case, the unilateral mandibular torus may indicate that twins $A$ isn't occluding evenly if he is bruxing on a normal basis.

When comparing twins where genetic factors are controlled for, one can shift the focus towards other factors that may cause dissimilarities between identical siblings, which includes epigenetic factors, maternal variables, and intrauterine forces. Epigentics refers to DNA methylation, acetylation, phosphorylation, ubiquitination, SUMOylation and histone modifications that reversibly alter DNA structure without changes to the DNA sequence. These changes accumulate over time as they are transmitted through mitosis. While de novo methylation by DNA methyltransferase targets cytosine bases without apparent specificity, deletion of DNA methyltransferase genes (DMNT1) in mice causes global demethylation and apoptosis [7]. This shows how there is a certain randomness that can have far reaching effects, which may lead to phenotypic differences between twins. The earlier the zygote splits, the sooner twins develop independently, with even the slightest DNA modification having the potential to generate drastic developmental consequences in later periods. While the etiology of epigenetic changes needs further study, there is a connection between methylation and chemical exposure, which may translate to an attempt at environmental adaptation [8]. A study to assess the extent of DNA methylation and histone acetylation in the genomes of 40 pairs of monozygotic twins found that epigenetic profiles were almost identical in $65 \%$ of the twin pairs and significant differences in the remaining $35 \%$ of twin pairs [9]. Accordingly, the amount of epigenetic differences was directly correlated to the age of the twins and the amount of time co-twins spent apart. As such, epigenetics may play a huge role in why twins $A$ and $B$ start to look progressively different as they age in figure 1.

Intrauterine factors have also been suspected to play a role in phenotypic differences between twins, especially in regards to intrauterine special constraint, which are common during twin fetal development and may also lead to deviations in facial development between twins. This is depicted in one study in which restraint stress was applied to a group of pregnant rat study models to determine the extent of any changes in craniofacial growth patterns in rat offspring that intrauterine stresses elicited [10]. The prenatally stressed group experienced increases in anterior cranial base length and viscerocranium measures with backward rotation of the midface and decreased flattening of the cranial vault. In this case prenatal chronic stress ultimately promoted endochondral growth in the cranial base and nasal septum.

Finally, maternal variables also play a key role in difference in dentofacial development. The effects from maternal exposure to nitrosatable drugs, fertility treat- ments, and nutrition intake such as folic acid intake may lead to epigenetic changes that are distributed unequally to developing twins in utero, potentially affecting dentofacial formation. Folic acid consumption for example affects neural tube closure, which in turn impacts brain and craniofacial structures later on in development [11].

In conclusion, this study brings attention to the genetic, epigenetic, as well as the environmental impacts on development and allows one to fully appreciate the multifactorial forces of this process. This can aid in patient education in terms of what can and can't be definitively passed down to the offspring. While genetics are often the prime suspect in rationalizing phenotypic manifestations, it is important for patients to be aware of other environmental factors that occur after conception that may also ultimately influence dentofacial presentations.

\section{References}

1. Horowitz SL, Osborne RH, DeGeorge FV. A cephalometric study of craniofacial variation in adult twins. Angle Orthod. 1960;30:1-5.

2. Cassidy KM, Harris EF, Tolley EA, Keim RG. Genetic influence on dental arch form in orthodontic patients. Angle Orthod. 1998 Oct;68(5):445-54. PubMed PMID: 9770103.

3. Lundström A. Nature versus nurture in dento-facial variation. 
Eur J Orthod. 1984 May;6(2):77-

91. PubMed PMID: 6587973.

4. Sognnaes RF, Rawson RD, Gratt BM, Nguyen NB. Computer comparison of bitemark patterns in identical twins. J Am Dent Assoc. 1982 Sep;105(3):449-51. PubMed PMID: 6957451.

5. Curtner RM. Predetermination of the adult face. Am J Or-

thod. 1953;39:201-217

6. Hunter WS. A study of the inheritance of craniofacial characteristics as seen in lateral cephalograms of 72 like-sexed twins. Rep Congr Eur Orthod Soc.1965;41:5970. PubMed PMID: 5222375.

7. Singh SM, Murphy B, O'Reilly R. Epigenetic contributors to the discordance of monozygotic twins. Clin Genet. 2002 Aug;62(2):97103. Review. PubMed

PMID:12220446.

8. Poulsen $P$, Esteller $M$, Vaag $A$, Fraga MF. The epigenetic basis of twin discordance in age-related diseases. Pediatr Res. 2007 May;61(5 Pt 2):38R-42R.Review. PubMed PMID: 17413848.

9. Fraga MF, Ballestar E, Paz MF, Ropero S, Setien F, Ballestar ML, Heine-Suñer D, Cigudosa JC, Urioste $\mathrm{M}$, Benitez J, Boix-Chornet $\mathrm{M}$, Sanchez-Aguilera A, Ling C, Carlsson $E$, Poulsen $P$, Vaag A, Stephan $Z$, Spector TD, Wu YZ, Plass C, Esteller $\mathrm{M}$. Epigenetic differences arise during the lifetime of monozygotic twins. Proc Natl Acad Sci U S A. 2005 Jul 26;102(30):10604-9. PubMed
PMID: 16009939; PubMed Central PMCID: PMC1174919.

10. Aminabadi NA, Behroozian A, Talatahari E, Samiei M, SadighEteghad S, Shirazi S. Does prenatal restraint stress change the craniofacial growth pattern of rat offspring? Eur J Oral Sci. 2016 Feb;124(1):17-25. doi: 10.1111/eos.12230. PubMed PMID: 26620628.

11. Kappen C. Modeling anterior development in mice: diet as modulator of risk for neural tube defects. Am J Med Genet C Semin Med Genet. 2013 Nov;163C(4):333-56. doi: 10.1002/ajmg.c.31380. Review. PubMed PMID: 24124024; PubMed Central PMCID:

PMC4149464. 